\section{Blunt then blunted}

The UK Medical Research Council report earlier this week. Chris Sherwell reports

APART from being mere snapshots of the period they describe, annual reports suffer by emerging halfway through the following year. Introducing the first report since he became MRC Secretary, James Gowans quickly addressed one problem by communicating a vivid impression of the dynamic research. But the need to bring everyone up to date blunted the impact of the report's potent, if measured, criticisms of the way some of that research is now run.

The report, which is for the twelve months to March, describes the impact of a $£ 1$ million $(10 \%)$ cut in commissioned research from the Department of Health and Social Security (DHSS). It says the Council was "deeply concerned" at the size and suddenness of the reduction, which "disrupts financial planning and frustrates initiatives" and affects both commissioned and other research. But the outlook was now less bleak, Gowans told his audience. The DHSS would be giving back $£ 700,000$ next year, and the MRC "firmly expected" a 1.6\% real increase in its share of the Science Budget in the coming year.

Gowans was apparently concerned also to moderate the tone of the report's criticisms of the operation of the customer-contractor principle, under which the DHSS acquired control of one-fifth of the MRC's funds. A series of rhetorical questions in the report suggests that responsibility for any lack of orientation of research work to social objectives cannot be laid at the MRC's door. The report also describes at length how administrative work and accountability requirements have imposed heavy burdens and taken experts away from research-_"a high price to pay" for arrangements which could be achieved "with less (MRC) published its latest annual quality that informs current medical

formality and administrative expense".

Gowans amplified the first of these points and dwelt not at all on the second. He described specific casesthe latest being the Blood Group Reference Lab-of the MRC deciding to start something new and then handing it on to an enthusiastic government; the MRC, he said, was anticipating national needs long before the customer-contractor principle came along. The ease with which the MRC programme merged with DHSS requirements, he added, also vindicated the MRC's judgment; the DHSS wanted the MRC to do what it was doing anyway. But the conclusion he drew was that DHSS MRC relations were very close. The "one proviso" was a complaint about bureaucracy.

If these pulled punches reflect the happy amelioration of financial problems, other thrusts in the report indicate that additional anxieties remain. The organisation of clinical research is "becoming increasingly difficult" as the incentives for young doctors to do research have diminished, and there is an "apparent tendency to lose sight of research as a proper component of clinical training". An appropriate pattern of support for university research when universities are not expanding has also yet to emerge, and is "of crucial importance" if the flow of able young scientists into research is to continue; holding research teams of high quality together will be "increasingly difficult" unless the problem of low numbers being absorbed into permanent university appointments is solved.

In the stringent economic circumstances the Council describes its first priority as reducing long-term commitments in order to free money for new work. Competition for long-term support will thus be fierce, it says, but short-term awards will now increase, and it urges the scientific community to continue to apply for these.

On the subject of recombinant DNA experiments, the MRC says it is looking forward to receiving proposals (four

Five-year pattern of MRC expenditure

\begin{tabular}{lcccc}
\hline & Total Expenditure (fmillion) & Change $\%{ }^{1}$ & Real change $\%{ }^{3}$ \\
$\mathbf{1 9 7 2 - 7 3}$ & 28.510 & $(1.737)$ & +14.3 & +4.1 \\
$\mathbf{1 9 7 3 - 7 4}$ & 30.330 & $(5.765)$ & +6.4 & +2.5 \\
$\mathbf{1 9 7 4 - 7 5}$ & 36.293 & $(8.745)$ & 19.7 & -1.3 \\
$\mathbf{1 9 7 5 - 7 6}$ & 47.140 & $(13.148)$ & +29.9 & -0.9 \\
$\mathbf{1 9 7 6 - 7 7}$ & 52.166 & $(13.315)$ & 110.7 & +0.9 \\
\hline
\end{tabular}

1 Figures in brackets are income within the total from sources other than the MRC's allocation from the Science Budget (eg. government departments, health authorities)

2 Change in total expenditure over previous year (undeflated)

3 Change, in real terms, of MRC allocation from the Science Budget, over previous year large project grants have already been made to universities); "high priority" should be given to the provision of centralised facilities for category III and IV experiments. The MRC in fact has no plans to build a category IV facility. The future of the only one in the country, the Microbiological Research Establishment at Porton, is now under consideration by the government. An MRC committee set up to examine the possibilities it offers is due to report soon.

\section{Research report}

ThF massive UK Department of the Environment (DOE) last week released a slim fourth annual report on research and development-covering a period that ended a full 18 months ago. A press release accompanying the report, which deals with the last full year before the department was divided into the Departments of Environment and Transport and before Martin Holdgate succeeded Dennis Lyons as Director General of Research, does not explain the delay. But it does advise, without amplification, that recent organisational changes under Holdgate will be described in the 1976-77 report. Holdgate is also expected to outline them to the press next week.

In the meantime, some of the details are available in the September issue of Environment and Transport World, the newspaper of the two departments. They are not exactly minor but, unsurprisingly perhaps, a couple are apparently mere name changes; thus, the Directorate of Research Requirements has become the Directorate of Research Policy, and the Research Secretariat has become the Research Administration Division. The Systems Analysis Research Unit (SARU), on the other hand, which has been looking at global problems (see page 356 ), has not changed its name but is, according to the paper, "increasingly turning its attention to problems on the domestic front".

Perhaps the most important change is the reduction from fifteen to six in the number of internal Research Requirements Committees. These will consist of what Holdgate calls "triads", three-man teams with a representative from the policy side who want particular work done ('customers'), from department research establishments or other research centres ('contractors'), and from the central research policy division. The six committees embrace areas controlled by senior civil servants like planning, countryside and resources, transport, construction and environmental protection.

As for last week's report, it says expenditure on research (at a peak of some $\mathrm{f} 45$ million for 1976-77, of which about a quarter went on environmental pollution and resources) is expected to decline sharply to a level in 1978-79 close to that five years ago. This, it says, is a result of constraints on public expenditure and reductions in civil service manpower.

Chris Sherwell 